\title{
MONITORING VINEYARDS WITH UAV AND MULTI-SENSORS FOR THE ASSESSMENT OF WATER STRESS AND GRAPE MATURITY
}

\begin{tabular}{|r|l|}
\hline Journal: & Journal of Unmanned Vehicle Systems \\
\hline Manuscript ID & juvs-2016-0024.R1 \\
\hline Manuscript Type: & Article \\
\hline Date Submitted by the Author: & $26-J a n-2017$ \\
\hline Complete List of Authors: & $\begin{array}{l}\text { Soubry, Irini; The Aristotle University } \\
\text { Patias, Petros; The Aristotle University, ; Professor } \\
\text { Tsioukas, Vasilios; The Aristotle University }\end{array}$ \\
\hline Keyword: & UAV, multispectral camera, NIR camera, viticulture, water stress \\
\hline Please Select from this Special & \\
Issues list if applicable: & \\
\hline
\end{tabular}

\section{SCHOLARONE ${ }^{\text {m }}$ \\ Manuscripts}




\section{MONITORING VINEYARDS WITH UAV AND MULTI- SENSORS FOR THE ASSESSMENT OF WATER STRESS AND GRAPE MATURITY}

I. Soubry, P. Patias, V. Tsioukas

The Aristotle University, School of Engineering, Thessaloniki, Greece

Department of Surveying Engineering, esoumpri@topo.auth.gr, patias@auth.gr, tsioukas@auth.gr

\section{ABSTRACT}

This paper deals with the monitoring of vineyards for the assessment of water stress and grape maturity using an Unmanned Aerial Vehicle (UAV) equiped with multispectral/infrared and Red-Green-Blue (RGB) cameras. The study area is the Gerovassiliou winery in the region of Epanomi, Greece cultivated with the local grape variety of Malagouzia. Fifteen flights were conducted with a fixed-wing UAV during the months of April to August 2015 with a mean interval of two weeks. The flights images were photogrammetrically processed for the production of orthoimages and then used to extract indices for the detection of water stress. Grape samples were collected two days before harvest and then analyzed and correlated with remote sensing indices. The TCARI/OSAVI index showed the best correlation with the grape samples in regards with maturity and the likelihood of water stress. Furthermore, the final results were of high resolution as far as farm purposes are concerned (a scale of 1:500 for all three sensors). These facts suggest that the instruments used in this study represent a fast, reliable and efficient solution to the evaluation of crops for agricultural applications.

Keywords: UAV, multispectral camera, NIR camera, RGB camera, viticulture, spectral indices, water stress, grape maturity 


\section{Introduction}

Manned aircrafts and satellites are currently the main platforms for acquiring remote sensing images. However, these systems have significant drawbacks in agricultural applications, such as low spatial resolution, limited availability due to weather conditions and high cost. Unmanned aerial vehicles (UAVs) have shown promising possibilities for the collection of agricultural remote sensing data as they can fly under the clouds, repeatedly, fast with low cost and safer conditions than a manned plane. Furthermore, they are flexible in regard to height and flight time and they produce very high resolution results that are appropriate for plant observation, which until now was not possible (Xiang \& Tian, 2011).

Previous studies, relevant to the topic of this study, include the classification of vegetation categories (Haboudane et al., 2002, Nebiker et al., 2008, Huang, Lan \& Hoffmann, 2008, Berni, Zarco-Tejada, Suarez, Fereres, 2009, Hunt et al., 2010, Knoth, Prinz, Loef, 2010, Laliberte, Goforth, Steele, Rango, 2011, Laliberte \& Rango, 2011, Melamed, 2014), the calibration of a multispectral camera (Del Pozo, Rodríguez-Gonzálvez, Hernández-López, Felipe-García, 2014) and change detection in ecosystems (Ihse, 2007).

More specifically, surveys of viticulture include the usage of airborne multispectral data for the improvement of vineyard management through vegetation monitoring. They mainly concern the use of satellite imagery and an infrared, multispectral or thermal camera coupled with an unmanned aerial system. Furthermore, they are related to mapping of leaf structure

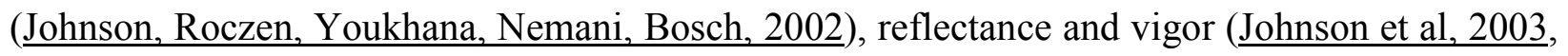
Costa Ferreira et al., 2007, Taskos et al., 2014), vegetation indices (Remondino, et al., 2011, Aranha, Maderia, Soares, Viana, Henriques, 2013, Candiago et al., 2015), estimation of water

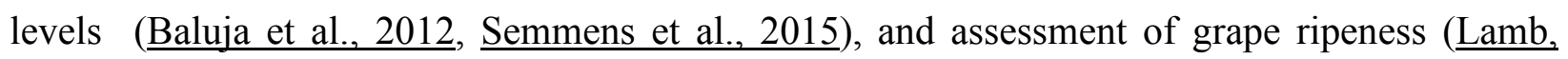


Weedon, Bramley, 2004, Agati G. et al., 2013). Up to now, only few researches involve the assessment of water stress in vineyards

The methodologies used in these preceding studies use indices and classification models and the results of viticulture studies are usually photomaps that separate vineyard varieties and maps of yield or crop vigor (Martinez-Casasnovas, Agelet-Fernandez, Arno, Ramos, 2012). However, research on the combined use of multiple sensors is limited, and this fact introduces a challenge regarding the alignment of these sensors.

In the present study, an UAV is used along with multispectral, infrared and RGB cameras for the monitoring of the condition of a vineyard until harvest. It is known that drought is a common stressor for wine production in many countries with low rain levels and high evaporation, the same applies to the area of Epanomi, where the flights were conducted. Water stress may adversely affect the development, performance and consistency of the grape and the taste properties of wine. Because of this, irrigation improvement is the main subject of research in wine producing countries (Baluja et al., 2012), such as Greece. A second important issue in a vineyard is the determination of the exact point of grape ripeness in order to evaluate the right time to harvest

On this basis, the issues that are raised are three:

- Is it possible to detect water stress using the above equipment?

- Is it possible to identify the point in time of grape maturity?

- To which accuracy can the above analysis be made?

\section{Materials and methods}

Vineyard site 
To answer the above questions, flights were conducted above the vineyards of the estate of Gerovassiliou (Epanomi, Greece) from April until August 2015; specifically the white grape variety of Malagouzia was analyzed. The data was collected using three different cameras (RGB, NIR, MultiSPEC) during fifteen flights with a two week gap (on average) between them using a fixed-wing UAV. The extend of the variety Malagouzia is about eighty acres and has an elevation that ranges from 82 to $98 \mathrm{~m}$ above sea level.

\section{Materials}

The RGB and Near Infrared (NIR) cameras had a 12 megapixel (MP) resolution and the multispectral (MultiSPEC) camera a 1.2 MP resolution for each spectrum (see Table 1, $2 \& 3$ ). The RGB camera consisted of three bands: Blue $(450 \mathrm{~nm})$, Green $(520 \mathrm{~nm})$ and Red (660nm) as well as the NIR camera: Green $(550 \mathrm{~nm}), \operatorname{Red}(625 \mathrm{~nm})$ and NIR $(850 \mathrm{~nm})$, whilst the MultiSPEC camera is composed by the Green $(510 \mathrm{~nm})$, Red $(650 \mathrm{~nm})$, Red Edge (710 nm) and NIR (790 $\mathrm{nm}$ ) bands. The UAV used is a fixed-wing aircraft of $0.7 \mathrm{~kg}$ with a wingspan of $96 \mathrm{~cm}$ that includes a radio link, an inertial measurement unit and an onboard Geographic Positioning System (GPS) (see Table 4). Also a Global Navigation Satellite System (GNSS) receiver was used to measure accurately the ground control points (GCPs) and the grape sample locations.

\section{Remotely sensed image acquisition and processing}

The first flight was conducted mid-March (after pruning) at approximately 11:30 under clear sky conditions, as were the following flights (in a timespan from 10:00 to 12:00 o' clock in order not to have very different solar positions). The climate variables during the flights season were high sunshine with temperatures from $8{ }^{\circ} \mathrm{C}$ till $26^{\circ} \mathrm{C}$ and infrequent rainfalls (only 1 day of heavy rain $-45.2 \mathrm{~mm}$ in August and 21 small rainfalls below $10 \mathrm{~mm}$ during the rest of the season of the flights) contributing to the drought phenomenon. Before the first flight 8 GCP 
points were positioned in good distribution and afterwards measured with the Real Time Kinematic (RTK) GNSS method, they remained on the vineyard during the whole flight season. The format of the GCP was a black square of $15 \times 15 \mathrm{~cm}$ in the center of a white background on an A3 sized paper (see Figure 1). The flight height for the RGB camera had a range from 115 to $170 \mathrm{~m}$, for the NIR camera from 170 to $260 \mathrm{~m}$ and for the MultiSPEC camera from 115 to 190 m. Furthermore, all flights were based on way-points and had a lateral overlap of 60 or $65 \%$ and a forward overlap of 75 or $80 \%$.

Aerial Triangulation by Bundle Block adjustment for all images of each flight mission was performed with Agisoft Photoscan Professional (RGB and NIR flights) and Pix4D software (multiSPEC flights). All images were aligned and rectified and a final orthomosaic of each flight was produced in the Greek Geodetic Reference System 1987(GGRS87). The cameras were autocalibrated by Agisoft except for the multiSPEC camera for which a field calibration was necessary prior to each flight. More specifically, it consists of a spectral field calibration, with the eMotion software, in the beginning of each flight at which a few pictures are taken at a $0.5-$ 1 meter distance from the ground. Worth noting is the fact that the processing of the multispectral images with the Agisoft software resulted in misalignment errors (see Figure 2), this is probably due to the fact that the calibration settings of the MultiSPEC camera cannot be recognized by this software. Therefore these images were processed with Pix4D in which the calibration information of the sensors could be processed.

The ground pixel size of the produced orthoimages ranges from 0.04 to $0.07 \mathrm{~m}$ for the RBG orthoimages, from 0.07 to $0.10 \mathrm{~m}$ for the NIR orthoimages and from 0.04 to 0.14 for the multiSPEC orthoimages. In order for all the orthoimages from the same camera to have the same pixel size, a precise resampling method, using bilinear interpolation, was conducted with the 
Erdas Image software. As a result, the RBG category has a resolution of $7 \mathrm{~cm} /$ pixel, the NIR category $10 \mathrm{~cm} /$ pixel and the multiSPEC category $14 \mathrm{~cm} /$ pixel.

The next step was the calculation of vegetation structural indices (DVI, NDVI, NDVIre, RDVI, GNDVI, MSR) for the possible recognition of changes in the structure of leaves due to water stress, the soil adjusted vegetation index (OSAVI), chlorophyll absorption in reflectance indices (MCARI, TCARI), the triangulation vegetation index (MTVI1) and chlorophyll index (CI). It is known that chlorophyll provides the mechanism for photosynthetic reactions as it is connected to the absorption of sunlight. Therefore it is directly connected to the plant capability of photosynthesis and productivity. More specifically, the amount of chlorophyll in the leaves is closely related to the stress and age of the plant. For the OSAVI index, an adjustment factor L is used for the crown background of the foliage. This factor depends on the density of vegetation, a low value is used in high vegetation areas. A value of $\mathrm{L}=0.25$ was used as suggested in a survey by Candiago et al., 2015 in a vineyard area. Also, the MCARI and TCARI indices where used in combination with the OSAVI and MTVI1 indices in order to eliminate the influence of soil and sparse vegetation respectively. (for the formulas of the indices see Table 5)

More specifically, the TCARI/OSAVI index was used, as proposed by several studies (Zarco-Tejada, González-Dugo, Berni, 2011, Zarco-Tejada et al., 2013, Gago et al., 2015), which seems to be sensitive to stress levels and free from soil reflectance, the zenith angle of the sun and the vigor of the plant. Furthermore, the MCARI/MTVI1 index was calculated in the same way Melamed, 2014 did, in order to eliminate the vegetation density and reveal regions with low chlorophyll levels. Finally, a combined optical index was calculated, the Greenness index, which is sensitive to chlorophyll content and provides a direct solution for the evaluation of vegetation 
by means of a low-cost aerial platform (Hunt et al., 2012). The above indices were calculated with the Model Maker tool from the Erdas Imagine suite.

Each index image (13 above indices for each orthoimage) was classified with the ISODATA classification method to allow the extraction of thematic information. The value for low vegetation height in the vegetation indices ranged from 0.10 to 0.35 and for high vegetation height from 0.80 to 1.00 . Also, the combined indices (TCARI/OSAVI and MCARI/MTVI1) were separated into two groups, no stress: 0.40-0. 64 and possible stress: $0.65-1.00$. Each classified group was colored appropriately and then mapped into a scale of 1: 500 (see Figure 3).

\section{Grape maturity estimation and sampling}

Grape samples were collected two days before harvest from twelve different regions in the vineyards variety of Malagouzia. Six of these had indications of possible stress (from the TCARI/OSAVI index) and the other six seemed healthy (see Figure 4). Each sample consisted of twenty grapes for which potential Hydrogen $(\mathrm{pH})$ and ${ }^{\circ}$ BRIX values were calculated. The ${ }^{\circ}$ BRIX values are a measure of fruit sugar content and an indicator of the degree of maturity. The balance between sugars and acids is considered a most critical parameter in the quality of wine production, therefore both sugar rate and $\mathrm{pH}$ of grapes are evaluated to determine their maturity (see Table 6). Of course, what is defined as "mature" differs depending on the type of wine produced and on what the producer believes to be the optimal maturity (Bisson, 2011).

\section{Results}

\section{Analysis of indices}

After the calculation of the indices, maps were created for each date of flight. The vegetation indices (NDVI, MSR) had similar results as far as their correlation with the BRIX value was concerned $\left(\mathrm{R}^{2}\right.$ from 0.33 to 0.41$)$. Therefore only the RDVI, NDVIre and GNDVI 
indices were mapped. The RDVI index had the lowest value in May and reached its peak in August and had a correlation with BRIX of $\mathrm{R}^{2}=0.52$, as for the NDVIre index, high and very high vegetation is also at its maximum in August and had $\mathrm{R}^{2}=0.54$, the GNDVI index, on the other hand, shows maximum values at the end of July but follows the same pattern of the RDVI index and has $\mathrm{R}^{2}=0.5$.

Furthermore, the combined indices indicate that the date of harvest (20/08/15) was the optimum. The TCARI/OSAVI index states this clearly through the comparison of the index two days before harvest, at which point a possibility of water stress was prominent $\left(\mathrm{R}^{2}=0.7\right)$, and at the day of the harvest, at which no sign of water stress was visible (see Figure 5). On the contrary, the MCARI/MTVI1 index did not show high levels of water stress throughout the whole season $\left(\mathrm{R}^{2}=0.25\right.$ two days before harvest with prominent water stress $)$, and is therefore not helpful for estimating the proper harvest date.

As for the CI index, it showed an estimation of the chlorophyll content but had no differentiation in general $\left(\mathrm{R}^{2}=0.15\right.$ two days before harvest with prominent water stress $)$, for this reason this index was not taken into account. Finally, the Greenness index classified most pixels into medium levels of vegetation which does not agree with the previous indices. However, it remains a good optical index for a general classification of chlorophyll content in the case were only the visible parts of the spectrum are available.

\section{Sample correlation}

As for the correlation of the sample results and the TCARI/OSAVI index regarding the maturity of the grape, it seems that there is a small average difference of 0.7 between the BRIX values of the so called "immature" grapes and the "mature" grapes, also the pH values of the “immature” grapes are slightly more acidic (by 0.2). (see Diagram 1) 


\section{Photo interpretation of results}

At this stage, a visual analysis of the produced orthoimagery was conducted. Initially, the development of the vine whilst the vegetation in increasing, listing the RGB orthoimagery, is visible. In March, the plants have just come out and the vineyard has the color of the soil, then in May the growth of the region appears to have begun as its color is light green. In the next phase in June the plants have well developed and covered the whole estate with leaves which now seem intensely green. This can be justified by the changes in reflectance in the green band from $93 \mathrm{~nm}$ to 171 during the period from April till August. (see Figure 6)

For the NIR and MultiSPEC orthoimagery the color analysis is different. More specifically, the guide for understanding, interpreting and benefiting from Color Infrared (CIR) imagery from the GICC by SMAC, 2011 was used. In the MultiSPEC orthoimagery the vegetation has a light pink color in May, which means that there is small amount of chlorophyll, further in the season (begin July), it acquires a dark red color, thus produces large amounts of chlorophyll. Changes in the NIR band are connected to plant health, high values are deep red, and thus healthy. On the other hand high values in the Red and Red Edge band indicate unhealthy vegetation or vegetation that is at the end of its period. Two days before harvest, some blue and green areas are visible, this reveals that the vegetation has begun to fade, while in the tan and magenta areas the vegetation may not be very healthy. Finally, at the day of harvest, the entire area is getting a deep red color which can be interpreted as dense vegetation with a large amount of chlorophyll. (see Figure 7)

As far as the soil is concerned, the color is white, gray with a little of blue. So probably the soil is mostly sandy with some clay areas. This was confirmed by the agronomist of the property according to whom the soil is mainly sandy with clay and limestone substrates. Finally, 
the NIR orthoimagery depicts the growth of vegetation during the month of July, in which the vegetation color evolves from light pink to dark red (see Figure 8). It seems from the above that the color interpretation of orthoimagery itself can also be very helpful in order to draw conclusions on the state of the vegetation and the type of soil.

\section{Discussion}

First of all, it is important to say that the final geometric accuracy of the product was very good considering the purposes of this investigation. For the RGB orthoimagery an optimal spatial resolution of $4 \mathrm{~cm}$ was achieved, respectively, for the multispectral orthoimagery it was 5 $\mathrm{cm}$ and for the near-infrared orthoimagery $12 \mathrm{~cm}$. This resolution is above the agronomic requirements of a vineyard, therefore, the final maps produced have a spatial resolution of $12 \mathrm{~cm}$ for a 1:500 scale wherever possible.

From the qualitative and quantitative analysis and cooperation with winegrowers of the study area, correlations between measured sugar levels and the $\mathrm{pH}$ of the grapes with the calculated maturity and stress levels of the plants where achieved and spatial differentiations emerged within each vineyard and resulted in the conduction of successful selective harvesting. However, for a precise quantitative assessment of the results, extensive simultaneous leaf and grape sampling is required.

More specifically, for the assessment of the water status of the plant, the TCARI/OSAVI index had the best correlation results with the sampling $\left(\mathrm{R}^{2}=0.7\right.$ between BRIX and TCARI/OSAVI).Also, the other vegetation indices were able to reconstruct the chlorophyll content of the plants. Moreover, it was possible to identify differences in the plants stage and to determine the soil composition through visual analysis. Finally, the exact point of grape maturity was traced and made the harvesting possible in the variety of Malagouzia. 
It is clear that the use of UAVs to monitor crops gives better geometric accuracy in comparison with satellite images and significantly reduces implementation costs. Moreover, the low flying height relative to other aerial platforms improves the resolution of the images. But, nevertheless, the small to medium size camera generally used in these systems, calls for a greater number of images to capture the same region in a corresponding resolution. Also, more flights are necessary in order to cover a large area because of the reduced flight time due to the change of batteries. Not to forget, the issue of stability and endurance plays an important role in windy areas. Finally, one of the major limitations is the lack of precise positioning of the camera which is required for the proper alignment of the aerial images.

Furthermore, improving the irrigation system in many wine producing countries with minimum rainfall becomes necessary, having in mind that the main vegetation stressor is drought. Thus, monitoring the water status of plants is not only useful for the detection of water stress, but also implements a correct and accurate irrigation system, while saving water and increasing some qualitative parameters of the cultivations.

Therefore, it has become clear that the use of UAVs in conjunction with sensors in the visible and infrared range is a very useful tool that can be tailored to precision farming and management of water irrigation. Increased monitoring could allow further crop management and perhaps even in conjunction with ground sensors, increase the productivity and quality of crops.

\section{Suggestions for further research}

Along with the dealing of the subject of this work, some concerns and suggestions emerged. Consequently, the main recommendations for further research are:

- The use of a more accurate method of aligning the bands of a multispectral camera. Implementing the Scale Invariant Feature Transform (SIFT) algorithm as Turner et al., 
2014 did, or the Local Weighted Mean Transform (LWMT) transformation like Laliberte et al., 2011 did.

- Monitoring vineyards with hyperspectral and thermal sensors. Thermal data makes it possible to monitor the water status of vines and is useful for distinguishing differences in soil moisture content and the identification of vegetation diseases. Moreover, a photochemical reflectance index (PRI) can be used to detect water stress while providing high spatial resolution in which the thermal bands lag. In a recent study Zarco-Tejada et al., 2013 proposed the use of a modified PRInorm index which showed a strong correlation with the stomatal leaf conduction (g) and the water stem potential (D).

- Applying the improved indices MSR (705,750), MCARI (705,750), TCARI/OSAVI (705,750), and MCARI/OSAVI $(705,750)$ as the survey of Wu C., Niu Z., Tang Q.. Huang W., 2008 suggests. These bands have proved to be more suitable in estimating the chlorophyll content.

- Usage of a combined system for monitoring the water needs of crops which comprises of an infrared sensor, recording the foliar temperature, a soil moisture sensor, where the amount of water can be noticed and a evapotranspiration recording system, which gives an indication of the amount of water that is required to be added to the soil.

In conclusion, this paper shows that the use of remote sensing as a crop monitoring tool could attract the interest of researchers and commercial organizations, as it offers the possibility of cost-effective usage of geospatial data, appropriate to support viticulture activities. However, the unlikeliness of discovering a unique maturity index that could be applied without discrimination to all growing conditions gives place to the historical experience with specific vineyards and farming areas and continues to be a critical factor in determining the grape 
maturity. An assumption could be made, that the use of modern technological means and the adoption of appropriate processing approaches could lead to an efficient semi-automated tool for the management of vine crops.

\section{Acknowledgements}

The authors would like to thank Ecodevelopment S.A for providing the equipment and especially thank Ms. Sandra Gewehr for her courtesy and kindness to help in the measurements and the communication with the winery. Thanks to the Gerovassiliou winery and to Mr. Argiris Agririou, the agronomist of the winery, for his knowledge on the vineyard.

\section{References}

Agati G., D’Onofrio C., Ducci E., Cuzzola A., Remorini D., Tuccio L., Lazzini F., Mattii G., 2013. Potential of a Multiparametric Optical Sensor for Determining in Situ the Maturity Components of Red and White Vitis vinifera Wine Grapes, American Chemical Society, Journal of Agricultural and Food Chemistry, A-H, doi: 10.1021/jf405099n

Aranha J., Maderia S., Soares R., Viana H., Henriques R., 2013. Caracterizacao e estratificacao de parcelas de vinha na regiao demarcada do douro dom recurso a forografias aereas captadas por um veiculo aerio nao tripulado. Revista informative da Ordem dos Engenheiros REGIAO NORTE. 13: 36-41.

Baluja J., Diago M. P., Balda P., Zorer R., Meggio F., Morales F., Tardaguila J., 2012. Assessment of vineyard water status variability by thermal and multispectral imagery using an unmanned aerial vehicle (UAV). Irrig. Sci 30: 511-522, doi: 10.1007/s00271-012-0382-9 
Berni J. A. J., Zarco-Tejada P. J., Suárez L., Fereres E., 2009. Thermal and Narrowband Multispectral Remote Sensing for Vegetation Monitoring From an Unmanned Aerial Vehicle, IEEE Transactions On Geoscience And Remote Sensing 47(3): 722-738

Bisson L., 2011. In search of optimal grape maturity, Department of Enology \& Viticulture, UC Davis, Practical Winery and Vineyard Journal, July/August issue 2001, Available from http://www.practicalwinery.com/julaug01p32.htm [accessed 07 September 2016].

Candiago S., Remondino F., De Giglio M., Dubbini M., Gattelli M., 2015. Evaluating Multispectral Images and Vegetation Indices for Precision Farming Applications from UAV Images, Remote Sens. 7: 4026-4047, doi: 10.3390/rs70404026

Costa Ferreira A.-M., Germain C., Homayouni S., Da Costa J.-P., Grenier G., Marguerit E., Roby J.-P., Van Leeuwen C, 2007. Transformation Of High Resolution Aerial Images In Vine Vigour Maps At Intra-Block Scale By Semi-Automatic Image Processing, XVth International GESCO meeting 20-23 June 2007, Porec, Croatia, pp. 1-7

Del Pozo S., Rodríguez-Gonzálvez P., Hernández-López D., Felipe-García B., 2014. Vicarious Radiometric Calibration of a Multispectral Camera on Board an Unmanned Aerial System, Remote Sens. 6: 1918-1937, doi: 10.3390/rs6031918

Gago J., Douthe C., Coopman R.E., Gallego P.P., Ribas-Carbo M., Flexas J., Escalona J., Medrano H., 2015. UAVs challenge to assess water stress for sustainable agriculture, Agricultural Water Management, Elsevier, 153: 9-19, doi: 10.1016/j.agwat.2015.01.020

Haboudane D., Millera R. J., Tremblay N., Zarco-Tejada P. J., Dextraze L., 2002. Integrated narrow-band vegetation indices for prediction of crop chlorophyll content for application to precision agriculture, Elsevier, Remote Sensing of Enviroment, 81: 416-426 
Huang Y., Lan Y., Hoffmann W.C., 2008. Use of Airborne Multi-Spectral Imagery for Areawide Pest Management, Agricultural Engineering International: the CIGR Ejournal, Manuscript IT 07 010. 10: 1-14

Hunt E. R. Jr., Hively W. D., Fujikawa S.J., Linden D. S., Daughtry C. S. T., Mc Carty G. W., 2010. Acquisition of NIR-Green-Blue Digital Photographs from Unmanned Aircraft for Crop Monitoring, Remote Sens. 2: 290-305, doi: 10.3390/rs2010290

Hunt E. R. Jr., Doraiswamy P. C., McMurtrey J. E., Daughtry C. S.T., Perry E. M., Akhmedov B., 2012. A visible band index for remote sensing leaf chlorophyll content at the canopy scale, International Journal of Applied Earth Observation and Geoinformation, Elsevier. 21: 103-112, doi: 10.1016/j.jag.2012.07.020

Ihse M., 2007. Colour infrared aerial photography as a tool for vegetation mapping and change detection in environmental studies of Nordic ecosystems: A review, Norsk Geografisk Tidsskrift_Norwegian Journal of Geography, Oslo. 61(4): 170-191, doi: $10.1080 / 00291950701709317$

Johnson L. F., Roczen D. E., Youkhana S. K., Nemani R. R., Bosch D. F., 2002. Mapping vineyard leaf area with multispectral satellite imagery, Elsevier: Computers and Electronics in Agriculture. 38(1): 33-44, doi: 10.1016/S0168-1699(02)00106-0

Johnson L. F., Herwitz S., Dunagana S., Lobitz B., Sullivana D., Slyea R., 2003. Collection of Ultra High Spatial and Spectral Resolution Image Data over California Vineyards with a Small UAV, Proceedings, Int'1 Symposium on Remote Sensing of Environment, pp. 1-3

Knoth C., Prinz T., Loef P., 2010. Microcopter-Based Color Infrared (CIR) Close Range Remote Sensing as a Subsidiary Tool for Precision Farming, Germany, pp. 1-7 
Laliberte A. S., Goforth M. A., Steele C. M., Rango A., 2011. Multispectral Remote Sensing from Unmanned Aircraft: Image Processing Workflows and Applications for Rangeland Environments, Remote Sens. 3: 2529-2551, doi: 10.3390/rs3112529

Laliberte A. S., Rango A., 2011. Image Processing and Classification Procedures for Analysis of Sub-decimeter Imagery Acquired with an Unmanned Aircraft over Arid Rangelands, GIScience \& Remote Sensing, 48(1): 4-23, doi: 10.2747/1548-1603.48.1.4

Lamb D. W., Weedon M. M., Bramley R. G. V., 2004. Using remote sensing to predict phenolics and colour at harvest in a Cabernet Sauvignon vineyard: Timing observations against vine phenology and optimizing image resolution, Australian Journal of Grape and Wine Research, 10: $46-54$

Melamed S., 2014. Get More From Imagery, Using Remotely Sensed Data for Efficient Crop Monitoring, Case Study, PCI Geomatics

Nebiker S., Annen A., Scherrer M., Oesch D., 2008. A light-weight multispectral sensor for micro UAV - opportunities for very high resolution airborne remote sensing, The International Archives of the Photogrammetry, Remote Sensing and Spatial Information Sciences, Vol. XXXVII, Part B1, Beijing, China, pp. 1193-1200

[GICC] North Carolina Geographic Information Coordinating Council by the Statewide Mapping Advisory Committee [SMAC], 2011. Using Color Infrared (CIR) Imagery, A Guide for Understanding, Interpreting and Benefiting from CIR Imagery, Working Group for Orthophotography Planning, pp. 1-22

Remondino F., Barazzetti L., Nex F., Scaioni M., Sarazzi D., 2011. UAV Photogrammetry for mapping and $3 \mathrm{~d}$ modeling- current status and future perspectives, International Archives of the 
Photogrammetry, Remote Sensing and Spatial Information Sciences, Vol. XXXVIII-1/C22 UAV-g, Conference on Unmanned Aerial Vehicle in Geomatics, Zurich, Switzerland, pp. 1-7

Semmens K. A., Anderson M. C., Kustas W. P., Feng Gao, Alfieri J. G., Lynn McKee, Prueger J. H., Hain C. R., Cammalleri C., Yang Y., Xia T., Sanchez L., Alsina M. M., Vélez M., 2015. Monitoring daily evapotranspiration over two California vineyards using Landsat 8 in a multisensor data fusion approach, Remote Sensing of Environment, Elsevier, pp. 1-16, doi: 10.1016/j.rse.2015.10.025

Taskos D.G., Koundouras S., Stamatiadis S., Zioziou E., Nikolaou N., Karakioulakis K., Theodorou N., 2014. Using active canopy sensors and chlorophyll meters to estimate grapevine nitrogen status and productivity, Springer Science \& Business Media New York, Precision Agriculture, 16(1): 77-98, doi: 10.1007/s11119-014-9363-8

Turner D., Lucieer A., Malenovský Z., King D. H., Robinson S. A., 2014. Spatial CoRegistration of Ultra-High Resolution Visible, Multispectral and Thermal Images Acquired with a Micro-UAV over Antarctic Moss Beds, Remote Sens. 6(5): 4003-4024, doi: $10.3390 /$ rs 6054003

Wu C., Niu Z., Tang Q., Huang W., 2008. Estimating chlorophyll content from hyperspectral vegetation indices: Modeling and validation, Elsevier, Agricultural And Forest Meteorology, 148: 1230-1241, doi: 10.1016/j.agformet.2008.03.005

Xiang H. \& Tian L., 2011. Development of a low-cost agricultural remote sensing system based on an autonomous unmanned aerial vehicle (UAV), Biosystems Engineering, 108(2): 174-190, doi: 10.1016/j.biosystemseng.2010.11.010 
Zarco-Tejada P. J., González-Dugo V., Berni J.A.J., 2011. Fluorescence, temperature and narrow-band indices acquired from a UAV platform for water stress detection using a microhyperspectral imager and a thermal camera, Remote Sensing of Environment, Elsevier, 117: 322337, doi: 10.1016/j.rse.2011.10.007

Zarco-Tejada P.J., González-Dugo V., Williams L.E., Suárez L., Berni J.A.J., Goldhamer D., Fereres E., 2013. A PRI-based water stress index combining structural and chlorophyll effects: Assessment using diurnal narrow-band airborne imagery and the CWSI thermal index, Remote Sensing of Environment, Elsevier, 138: 38-50, doi: 10.1016/j.rse.2013.07.024 
Table 1 Specifications of the Canon S110 RGB camera

\begin{tabular}{ll}
\hline \multicolumn{2}{c}{ Canon S110 RGB } \\
\hline \multicolumn{2}{c}{ Technical Features } \\
\hline Resolution & $12 \mathrm{MP}$ \\
\hline Focal length & $60 \mathrm{~mm}$ \\
\hline Ground resolution at $\mathbf{1 0 0}$ m & $3.5 \mathrm{~cm} / \mathrm{px}$ \\
\hline Sensor size & $7.44 \times 5.58 \mathrm{~mm}$ \\
\hline Pixel pitch & $1.86 \mathrm{um}$ \\
\hline Image format Characteristics & JPEG and/or RAW \\
\hline \multicolumn{1}{c}{$* * * *$} \\
\hline High wind \& low light conditions* & $* * * *$ \\
\hline Usability* & $* * * * *$ \\
\hline Mission flight time* & $* * * *$ \\
\hline Optimized aerodynamic profile* & $* * * * *$ \\
\hline Orthomosaic \& DSM* & $* * * * *$ \\
\hline Ground Sampling Distance (GSD)* & $* * *$ \\
\hline Band precision* &
\end{tabular}

Table 2 Specifications of the Canon S110 NIR camera

\begin{tabular}{ll}
\hline \multicolumn{2}{c}{ Canon S110 NIR } \\
\hline \multicolumn{1}{c}{ Technical Features } \\
\hline Resolution & $12 \mathrm{MP}$ \\
\hline Focal length & $60 \mathrm{~mm}$ \\
\hline Ground resolution at $\mathbf{1 0 0} \mathbf{~ m}$ & $3.5 \mathrm{~cm} / \mathrm{px}$ \\
\hline Sensor size & 7.44 x $5.58 \mathrm{~mm}$ \\
\hline Pixel pitch & $1.86 \mathrm{um}$ \\
\hline Image format & JPEG and/or RAW \\
\hline \multicolumn{1}{c}{ Characteristics } \\
\hline $\begin{array}{l}\text { High wind \& low light } \\
\text { conditions* }\end{array}$ \\
\hline Usability* & $* * *$ \\
\hline Mission flight time* & $* * * *$ \\
\hline Optimized aerodynamic profile* & $* * * *$ \\
\hline Orthomosaic \& DSM* & $* * * * *$ \\
\hline $\begin{array}{l}\text { Ground Sampling Distance } \\
\text { (GSD)* }\end{array}$ & $* * * * *$ \\
\hline Band precision* & $* * *$
\end{tabular}


Table 3 Specifications of the multiSPEC 4C camera

multiSPEC 4C

\section{Technical Features}

\begin{tabular}{ll}
\hline Resolution & 4 sensors of $1.2 \mathrm{MP}$ \\
\hline Focal length & $35 \mathrm{~mm}$ \\
\hline Ground resolution at $\mathbf{1 0 0} \mathbf{~ m}$ & $10 \mathrm{~cm} / \mathrm{px}$ \\
\hline Sensor size & $4.8 \times 3.6 \mathrm{~mm}$ \\
\hline Pixel pitch & 3.75 \\
\hline Image format & $\mathrm{RAW}$ \\
\hline Upward looking irradiance sensor & Yes \\
\hline \multicolumn{1}{c}{ Characteristics } & \\
\hline High wind \& low light conditions* & $* * * * *$ \\
\hline Usability* & $* * * * *$ \\
\hline Mission flight time* & $* * *$ \\
\hline Optimized aerodynamic profile* & $* * *$ \\
\hline Orthomosaic \& DSM* & $* * *$ \\
\hline Ground Sampling Distance & $* * *$ \\
(GSD)* & $* * * * *$ \\
\hline Band precision* &
\end{tabular}

*Where: *=Lowest

$* *=$ Low

$* * *=$ Average

$* * * *=\mathrm{Good}$

$* * * * *=$ Excellent

Table 4 Specifications of the eBee drone

Technical Specifications of eBee

Hardware

\begin{tabular}{ll}
\hline Weight (inc. supplied camera) & Approx. 0.69 kg $(1.52 \mathrm{lbs})$ \\
\hline Wingspan & $96 \mathrm{~cm}(38 \mathrm{in})$ \\
\hline Material & $\begin{array}{l}\text { EPP foam, carbon structure \& } \\
\text { composite parts }\end{array}$ \\
\hline Propultion & $\begin{array}{l}\text { Electric pusher propeller, } 160 \mathrm{~W} \\
\text { brushless DC motor }\end{array}$ \\
\hline Battery & $11.1 \mathrm{~V}, 2150 \mathrm{mAh}$ \\
\hline Maximum flight time & Operation \\
\hline Nominal cruise speed & $50 \mathrm{minutes}$ \\
\hline Radio link range & $\begin{array}{l}40-90 \mathrm{~km} / \mathrm{h}(11-25 \mathrm{~m} / \mathrm{s} \text { or } 26-56 \\
\mathrm{mph})\end{array}$ \\
\hline Maximum coverage (single flight) & $\begin{array}{l}12 \mathrm{~km}{ }^{2}(\mathrm{at} 974 \mathrm{~m} / 3,195 \mathrm{ft} \text { altitude } \\
\text { AGL) }\end{array}$ \\
\hline
\end{tabular}




\begin{tabular}{|c|c|}
\hline Wind resistance & Up to $45 \mathrm{~km} / \mathrm{h}(12 \mathrm{~m} / \mathrm{s}$ or $28 \mathrm{mph})$ \\
\hline $\begin{array}{l}\text { Ground Sampling Distance } \\
\text { (GSD) }\end{array}$ & Down to $1.5 \mathrm{~cm}$ (0.6 in) per pixel \\
\hline $\begin{array}{l}\text { Relative orthomosaic/3D model } \\
\text { accuracy }\end{array}$ & $1-3 x$ GSD \\
\hline $\begin{array}{l}\text { Absolute horizontal/vertical } \\
\text { accuracy (w/GCPs) }\end{array}$ & Down to $3 \mathrm{~cm}(1.2 \mathrm{in}) / 5 \mathrm{~cm}$ ( 2 in) \\
\hline $\begin{array}{l}\text { Absolute horizontal/vertical } \\
\text { accuracy (no GCPs) }\end{array}$ & $1-5 \mathrm{~m}(3.3-16.4 \mathrm{ft})$ \\
\hline Multi-drone operation & $\begin{array}{l}\text { Yes (inc. mid-air collision } \\
\text { avoidance) }\end{array}$ \\
\hline Automatic 3D flight planning & Yes \\
\hline Linear landing accuracy & Approx. 5m (16.4ft) \\
\hline \multicolumn{2}{|c|}{ Software } \\
\hline Flight planning \& control & eMotion \\
\hline Image processing & Pix4Dmapper \\
\hline
\end{tabular}


Table 5 Formulas of the indices that were used for mapping with their references

\begin{tabular}{|c|c|c|c|c|c|}
\hline Index & Name & Formula & Range & Reason/Contribution & Reference \\
\hline NDVI & $\begin{array}{l}\text { Normalized Difference } \\
\text { Vegetation Index }\end{array}$ & $\left(\mathrm{R}_{\mathrm{NIR}}-\mathrm{R}_{\mathrm{RED}}\right) /\left(\mathrm{R}_{\mathrm{NIR}}+\mathrm{R}_{\mathrm{RED}}\right)$ & -1 to 1 & $\begin{array}{l}\text { Low values show disease or insufficient water } \\
\text { amounts }\end{array}$ & $\begin{array}{l}\text { Zarco-Tejada P. J., } \\
\text { González-Dugo V., Berni } \\
\text { J.A.J., } 2011\end{array}$ \\
\hline NDVIre & $\begin{array}{l}\text { Normalized Difference } \\
\text { Vegetation Index Red } \\
\text { Edge }\end{array}$ & $\left(\mathrm{R}_{\mathrm{NIR}}-\mathrm{R}_{\mathrm{RE}}\right) /\left(\mathrm{R}_{\mathrm{NIR}}+\mathrm{R}_{\mathrm{RE}}\right)$ & 0 to 1 & $\begin{array}{l}\text { More effective in assessing chlorophyll } \\
\text { content in vineyards }\end{array}$ & Taskos D.G. et al., 2014 \\
\hline GNDVI & $\begin{array}{l}\text { Green Normalized } \\
\text { Difference Vegetation } \\
\text { Index }\end{array}$ & $\left(\mathrm{R}_{\mathrm{NIR}}-\mathrm{R}_{\mathrm{GREEN}}\right) /\left(\mathrm{R}_{\mathrm{NIR}}+\mathrm{R}_{\mathrm{GREEN}}\right)$ & 0 to 1 & $\begin{array}{l}\text { Lineary correlated with the Leaf Area Index } \\
\text { (LAI) and biomass of the vegetation }\end{array}$ & Candiago S. et al., 2015 \\
\hline RDVI & $\begin{array}{l}\text { Renormalized Difference } \\
\text { Vegetation Index }\end{array}$ & $\left(\mathrm{R}_{\mathrm{NIR}}-\mathrm{R}_{\mathrm{RED}}\right) / \mathrm{sqrt}\left(\mathrm{R}_{\mathrm{NIR}}+\mathrm{R}_{\mathrm{RED}}\right)$ & 0 to 1 & More efficient for dense foliage & $\begin{array}{l}\text { Zarco-Tejada P. J., } \\
\text { González-Dugo V., Berni } \\
\text { J.A.J., } 2011\end{array}$ \\
\hline MSR & Modified Simple Ratio & $\begin{array}{c}\left(\mathrm{R}_{\mathrm{NIR}} / \mathrm{R}_{\mathrm{RED}}+1\right) / \\
{\left[\left(\mathrm{R}_{\mathrm{NIR}} / \mathrm{R}_{\mathrm{RED}}\right)^{0.5}+1\right]}\end{array}$ & 0 to 1 & $\begin{array}{l}\text { Improvement of RDVI and highly sensitive to } \\
\text { biophysical parameters of vegetation to which } \\
\text { it is linearly correlated to }\end{array}$ & $\begin{array}{l}\text { Zarco-Tejada P. J., } \\
\text { González-Dugo V., Berni } \\
\text { J.A.J., } 2011\end{array}$ \\
\hline OSAVI & $\begin{array}{l}\text { Optimized Soil-Adjusted } \\
\text { Vegetation Index }\end{array}$ & $\begin{array}{c}(1+0.25)^{*}\left(\mathrm{R}_{\mathrm{NIR}^{-}}\right. \\
\mathrm{R}_{\mathrm{RED})} /\left(\mathrm{R}_{\mathrm{NIR}}+\mathrm{R}_{\mathrm{RED}}+0.25\right)\end{array}$ & 0 to 1 & $\begin{array}{c}\text { Minimizes soil effects, used together with } \\
\text { TCARI index }\end{array}$ & Candiago S. et al., 2015 \\
\hline MCARI & $\begin{array}{l}\text { Modified Cab Absorption } \\
\text { in Reflectance Index }\end{array}$ & $\begin{array}{c}{\left[\left(\mathrm{R}_{\mathrm{RE}}-\mathrm{R}_{\mathrm{RED}}\right)-0.2 *\left(\mathrm{R}_{\mathrm{RE}}-\right.\right.} \\
\left.\left.\mathrm{R}_{\mathrm{GREEN}}\right)\right]^{*}\left(\mathrm{R}_{\mathrm{RE}} / \mathrm{R}_{\mathrm{RED}}\right)\end{array}$ & 0 to 1 & Estimates leaf chlorophyll content & Melamed S., 2014 \\
\hline TCARI & Transformed CARI & $\begin{array}{l}3 *\left[\left(\mathrm{R}_{\mathrm{RE}}-\mathrm{R}_{\mathrm{RED}}\right)-0.2 *\left(\mathrm{R}_{\mathrm{RE}^{-}}\right.\right. \\
\left.\left.\mathrm{R}_{\mathrm{GREEN}}\right) *\left(\mathrm{R}_{\mathrm{RE}} / \mathrm{R}_{\mathrm{RED}}\right)\right]\end{array}$ & 0 to 1 & Estimates leaf cholophyll content & $\begin{array}{l}\text { Zarco-Tejada P. J., } \\
\text { González-Dugo V., Berni } \\
\text { J.A.J., } 2011\end{array}$ \\
\hline MTVI1 & $\begin{array}{l}\text { Modified Triangulation } \\
\text { Vegetaion Index } 1\end{array}$ & $\begin{array}{l}1.2 *\left[1.2 *\left(\mathrm{R}_{\mathrm{NIR}}-\mathrm{R}_{\mathrm{GREEN}}\right)-\right. \\
\left.2.5^{*}\left(\mathrm{R}_{\mathrm{RED}}-\mathrm{R}_{\mathrm{GREEN}}\right)\right]\end{array}$ & 0 to 1 & $\begin{array}{l}\text { Sensitive to density of vegetation and not to } \\
\text { chlorophyll content, used with MCARI index }\end{array}$ & $\begin{array}{l}\text { Zarco-Tejada P. J., } \\
\text { González-Dugo V., Berni } \\
\text { J.A.J., } 2011\end{array}$ \\
\hline CI & Cab Index & $\left(\mathrm{R}_{\mathrm{NIR}} / \mathrm{R}_{\mathrm{RE}}\right)-1$ & 0 to 1 & $\begin{array}{c}\text { More effective in assesing cholophyll content } \\
\text { than NDVI index }\end{array}$ & Taskos D.G. et al., 2014 \\
\hline
\end{tabular}


Table 6 Values of each sample in BRIX and $\mathrm{pH}$

\begin{tabular}{cccc}
\hline \multirow{3}{*}{ Category } & $\begin{array}{c}\text { Sample } \\
\text { number }\end{array}$ & $\begin{array}{c}{ }^{\circ} \text { BRIX } \\
\text { or } \\
\text { TSS }\end{array}$ & pH \\
\hline \multirow{4}{*}{$\begin{array}{c}\text { Possible } \\
\text { stress }\end{array}$} & M1 & 10.85 & 3.54 \\
\cline { 2 - 4 } & M2 & 11.6 & 3.51 \\
\cline { 2 - 4 } & M3 & 10.9 & 3.48 \\
\cline { 2 - 4 } & M4 & 10.8 & 3.49 \\
\cline { 2 - 4 } & M5 & 11.3 & 3.46 \\
\hline \multirow{3}{*}{ Healthy } & M6 & 10.7 & 3.44 \\
\cline { 2 - 4 } & M7 & 11.3 & 3.57 \\
\cline { 2 - 4 } & M8 & 11.65 & 3.5 \\
\cline { 2 - 4 } & M10 & 12 & 3.49 \\
\cline { 2 - 4 } & M11 & 11.5 & 3.51 \\
\cline { 2 - 4 } & M12 & 11.5 & 3.48 \\
\hline
\end{tabular}

Diagram 1 Linear regression between the BRIX value and the TCARI/OSAVI index

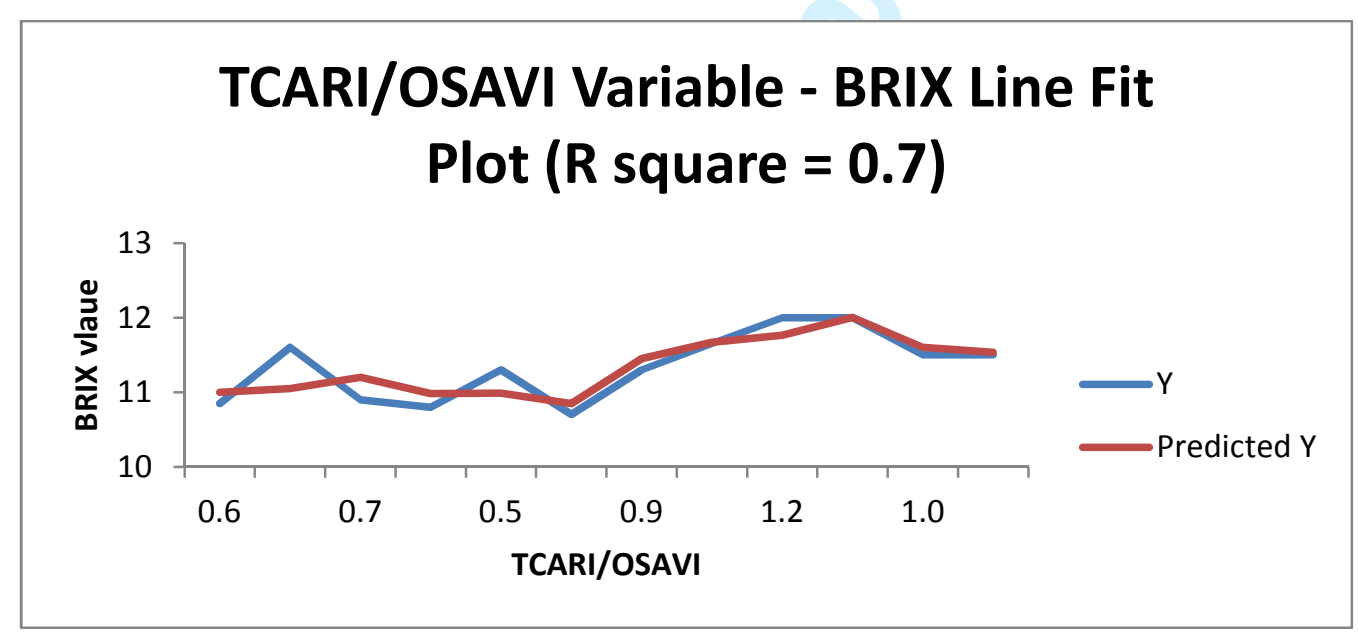




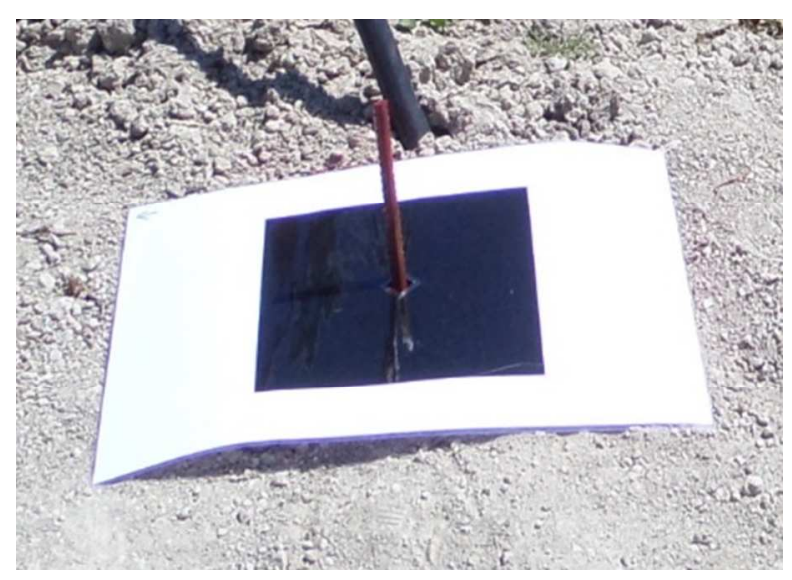

Figure 1 Example of used GCP

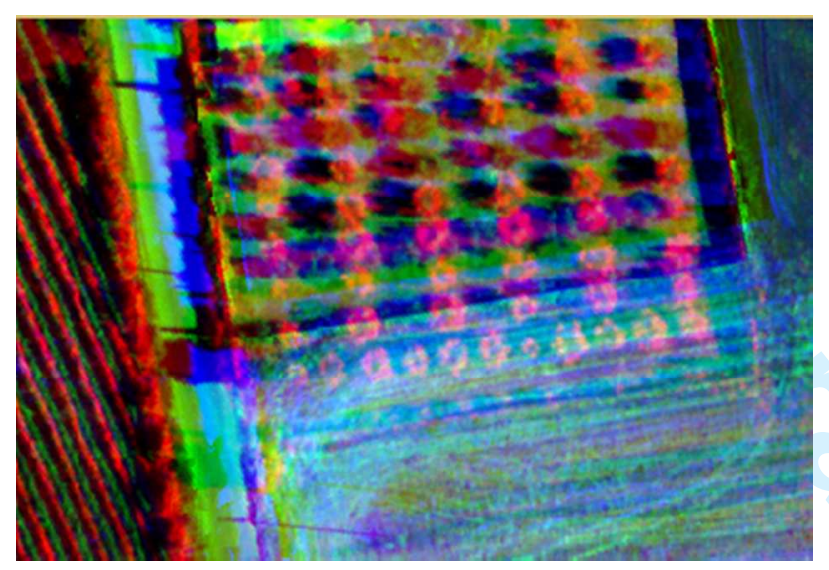

Figure 2 Example of bad alignment between the spectral bands of the multispectral images processed by Agisoft

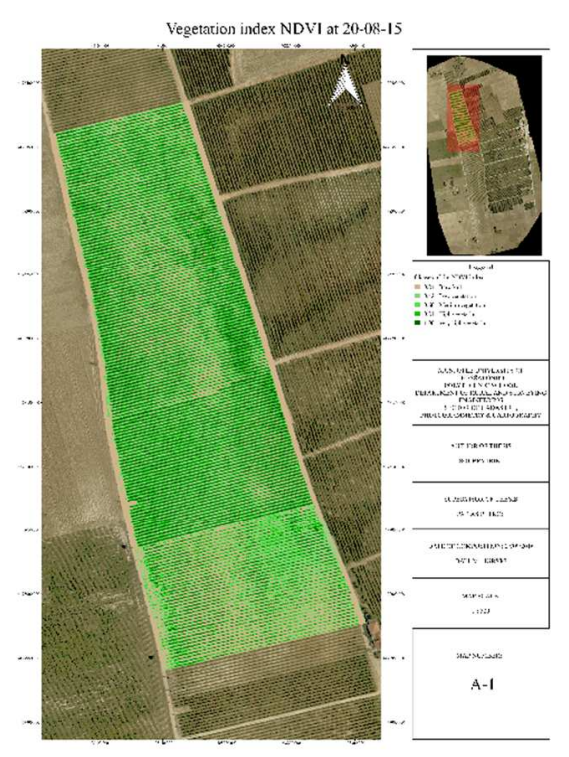

Figure 3 Example of an NDVI classified map at 20/08/15 
TCARI/OSAVI index and sample locations at 18-08-15

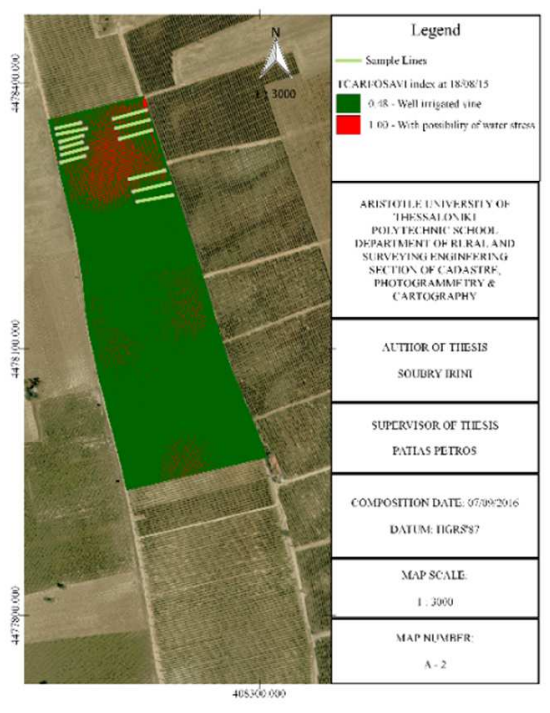

TCARI/OSAVI index and sample lines at 20/08/15

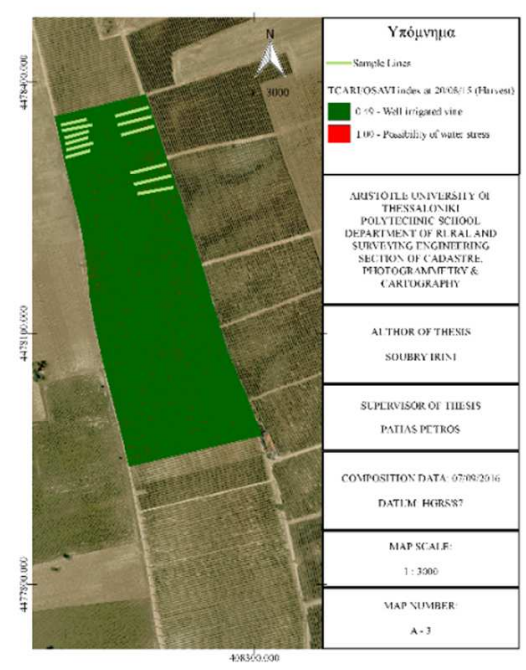

Figure 4 The classified TCARI/OSAVI index with the grape sampling lines at $18 / 08 / 15$

Figure 5 TCARI/OSAVI index at harvest 


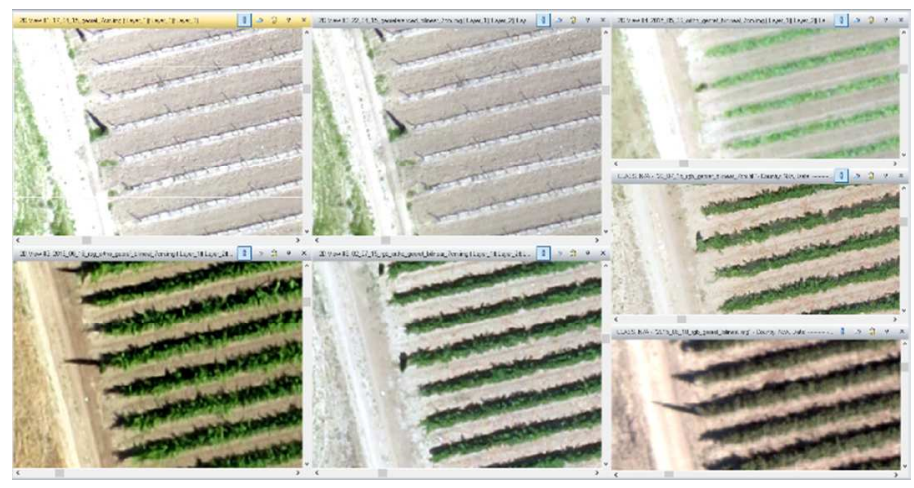

Figure 6 Photo interpretation of the RGB orthoimagery

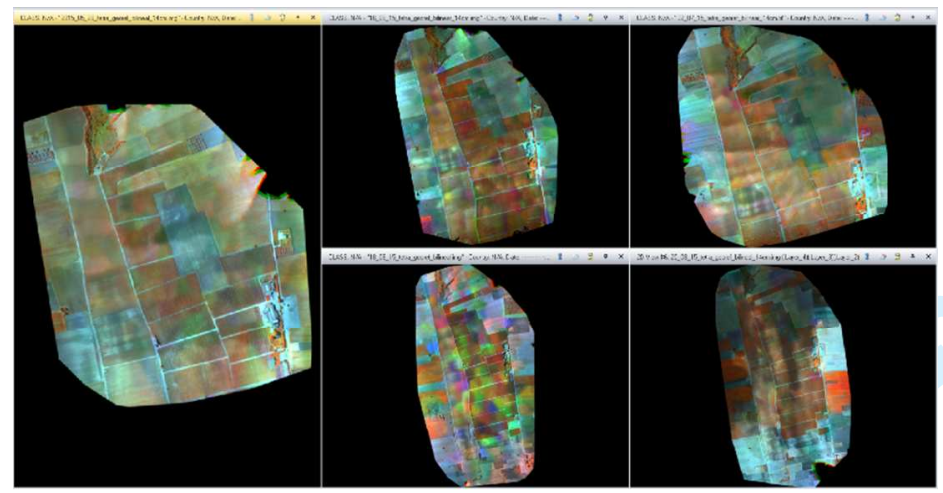

Figure 7 Photo interpretation of the MultiSPEC orthoimagery

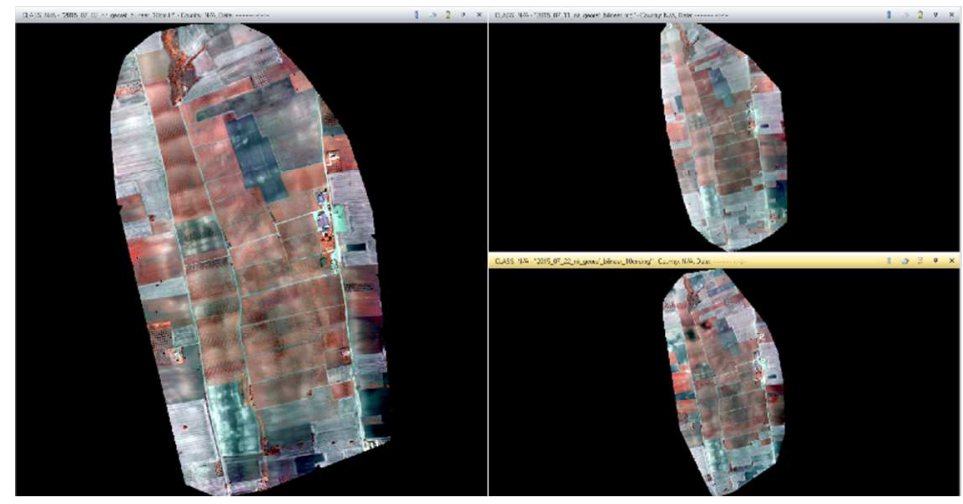

Figure 8 Photo interpretation of the NIR orthoimagery 